1 Khashe, S., Gerber, D. and Smith, I.F.C. "Surveying the Evolution of Computing in Architecture, Engineering and

2 Construction Education since 2012" J of Computing in Civil Engineering, Vol 30 No 6, 2016, pp 04016017-1-12

3 doi:10.1061/(ASCE)CP.1943-5487.0000580

4 http://cedb.asce.org

5 Copyright ASCE

\title{
Surveying the Evolution of Computing in Architecture, Engineering, and Construction Education since 2012
}

Saba Khashe ${ }^{1}$ and Environmental Engineering, 3620 S. Vermont Avenue, Los Angeles, CA 90089-2531. E-mail:

11 skhashe@usc.edu

David J. Gerber, A.M. ASCE ${ }^{2}$

13 Assistant Professor, University of Southern California, School of Architecture, and Viterbi School of Engineering,

14 Sonny Astani Dept. of Civil and Environmental Engineering, Watt Hall 316, Los Angeles, California 90089-0291.

Phone: +1-617-794-7367. E-mail: dgerber@usc.edu

17 Professor, Applied Computing and Mechanics Laboratory (IMAC), Civil Engineering Institute, School of (EPFL), Lausanne, 1015, Switzerland. E-mail: Ian.Smith@epfl.ch

CE Database subject headings: Architecture Education; Engineering Education; Computer Application; Information

21 Technology (IT); Curricula; Computer Programming; Computer Software; Design and Computing

\footnotetext{
${ }^{1}$ Graduate Student, University of Southern California, Viterbi School of Engineering, Sonny Astani Dept. of Civil and Environmental Engineering, 3620 S. Vermont Avenue, Los Angeles, CA 90089-2531. E-mail: skhashe@usc.edu.

${ }^{2}$ Assistant Professor, University of Southern California, School of Architecture, and Viterbi School of Engineering, Sonny Astani Dept. of Civil and Environmental Engineering Watt Hall 316, Los Angeles, California 90089-0291. Phone: +1-617-794-7367. E-mail: dgerber@usc.edu

${ }^{3}$ Professor, Applied Computing and Mechanics Laboratory (IMAC), Civil Engineering Institute, School of Architecture, Civil and Environmental Engineering (ENAC), Station 18, Swiss Federal Institute of Technology (EPFL), Lausanne, 1015, Switzerland. E-mail: Ian.Smith@epfl.ch
} 


\section{Abstract}

23 This paper presents the results of an online survey that was conducted in 2014 to assess the evolution of computing in 24 Architecture, Engineering, and Construction (AEC) education. A primary goal includes contributing to the 25 understanding of the evolution of computing in architecture, civil engineering, and construction management curricula. The current state of computing within the AEC curricula with respect to changes implemented since 2012

27 is evaluated. The paper includes a comparison of the 2014 survey with the 2012 survey. Changes in the levels and 28 concentrations of computer science knowledge versus computer skills in the curricula are investigated. Similarities and differences between architecture and engineering (including construction management) programs are studied through comparing the data associated with these disciplines. The survey results are presented as useful benchmarks for decision-making regarding research, industry collaboration, and understanding the speed and needs for change in AEC curricula. Key findings of the study include: (1) the importance of most computing skills and the coverage of curricula for these skills have not changed significantly over these two years, while the competence of the students in these skills have decreased; (2) increasing trends have been seen in the percentages of computer science knowledge related courses in all program types and levels; (3) the percentage of computing skills related courses are more than the percentages of the computer science knowledge related courses in AEC curricula; (4) an increasing trend has been seen in the importance of the knowledge of scientific concepts of computing in respondents' perceptions; and (5) computing education still is not sufficient to meet the demands of the AEC industry.

\section{Introduction}

Recent advances in computing play a growing and important role in nearly every architecture, engineering and construction (AEC) discipline. In this regard, future architects and engineers will be expected to contribute to and guide technological transformations for the industry. Integrating computing into the AEC curricula contributes to mastering this change by preparing AEC professionals to meet the emerging industry demands, however, the AEC industry continues to lag and adapt slowly to new opportunities (Stewart and Daet 2002; Bouchlaghem, and ElHamalawi 2006; Svavarsson et al. 2002). One of the reasons for this noted lag is the time spent on computing, and the content of computing courses within the spectrum of AEC curricula (Danijel and Tibaut 2005). Many architecture and

47 engineering educators believe that computing is only a skill to be acquired on the job, and critically not a science to be learnt in an academic setting. However, most AEC professionals also agree that there is a growing lack of 
correlation between what is taught and how architects and engineers use computers in practice (Smith 2003). Although computing in the AEC has become an established research area, the results are often not integrated into the curricula (Danijel and Tibaut 2005). Given the complex nexus of forces acting upon the AEC, such as economic changes, global market influences, and information technology that drive changes in industry, the AEC curricula are subject to frequent updates and where this is not the case should be. For our focus, most notably information technology and computing are going to be one of the most powerful catalysts for change (Veeramani and Russell 2000). Therefore, considering the increasing demand within the AEC for computing, an interdisciplinary computing focused approach to AEC curricula revision is relevant and prescient (Irizarry et al. 2010).

It is essential for curricular decision makers to measure and understand what future AEC professionals need to know about computing and what competencies are needed to ensure that AEC educators can prepare these students. To answer these questions, the authors seek the educators' perceptions regarding computing content and trends within the AEC curricula and its particular evolution. The authors solicited the opinions of the educators on the perception of computer science knowledge versus computer skills within AEC educational curricula. In the context of this study, a critical distinction and definition is used throughout, where 'computing skills' is defined as the ability to use computer-based technologies for AEC tasks, while 'computer science knowledge' is defined as the ability to appropriately apply the knowledge of, for example, data representations and algorithms to AEC related tasks. Furthermore, there is a growing trend for tool building, automation, and infusion of computer science into AEC practices making this distinction an important contribution and leading indicator (Ceccato 1999; Ceccato and AADipl 2005; Burry 2013; Burry et al. 2001).

The study reported on in this paper was conducted as a follow up to the previous studies conducted in 1986, 1989, 1995, 2002 and 2012 in order to provide insights into current educational environments and to provide greater understanding of the evolution of curricular demands. This paper reviews the previous work and continues with a description of the research approach and methodology previously adopted by the authors in 2012. Then, it discusses the data gathered through an online survey conducted in 2014, from which research directions and trends are discussed. These include: 1) defining the perceived importance of computing skills required for AEC students, competence of the students in these skills, and the coverage of curricula for these skills; 2) defining the perceived importance of computer science knowledge versus computer-skill educational approaches; 3) defining the perceived barriers and 
issues for better incorporating computing in the AEC curricula; and 4) defining the perceived future plans for the AEC education. Finally, a discussion of limitations and the needs for future research into AEC education is provided.

\section{$78 \quad$ Background and Objectives}

79 The early use of computer and information sciences in the AEC higher education setting is closely related to the introduction of programming languages (Tibaut et al. 2012a), which resulted in the emergence of an interdisciplinary

81 field that attempted to link computer science and AEC (Turk 2006). It manifested itself in the curricula and emerged 82 as a field which we call "computing in AEC curricula" in this paper. Advances in computer technology often raise 83 concerns regarding the preparation of AEC students to function effectively in new computing environments. To 84 address these concerns, the American Society of Civil Engineers' (ASCE) Task Committee on Computing Education 85 of the Technical Council on Computing and Information Technology (TCCIT) conducted a series of surveys in 1986, 1989, 1995, and 2002 to assess the current computing component of the curriculum in civil engineering. A review of

87 the focus areas of these studies and their findings can be found in the 2012 survey (Gerber et al. 2013). Considering the industry and technological trends enabling or forcing closer ties between the disciplines, the need for the integration of architecture into the discussion and more generally for identifying multidisciplinary approaches in the AEC industry was implemented in follow up survey conducted in 2012. This was performed upon the request of the ASCE TCCIT to assess the evolution of computing in AEC curricula.

The 2012 study recognized the importance of developing a better understanding of the interdependencies, overlaps, similarities and differences between AEC disciplines. In addition, the 2012 study investigated the levels and concentrations of computer science knowledge versus computer skills in the curricula across the disciplines. Again, the authors are highlighting a critical distinction, computer science knowledge versus computer skills, as it leads to

96 abilities to not only serve the industry needs in the present but also to affect the AEC industry's ability to adapt and

97 innovate over the long term. The 2012 survey also gathered information related to the prerequisites that are necessary for the fundamental training of students. Key findings of the 2012 study included: 1) the importance and coverage of computer skills and competence of students has increased over the past decade; 2) computing skills are judged to be more important than computer science knowledge in the AEC curricula; 3) several links between computer science 
than what educators desire; and 5) scientific concepts of computing are perceived as important for preparing architects and engineers for unknown future developments in information technology (Gerber et al. 2013). The results of the 2012 survey are considered as useful benchmarks for our comparison, trend analysis, and policy purposes in this paper and for the planned future work.

In addition to the surveys conducted by the ASCE, there are other studies conducted that have evaluated the computing components of the AEC curricula. These studies have emphasized the importance of integrating computer science and information technology in engineering education and have assessed the academic computing requirements for engineering programs in general. A number of important precedent studies discussed how computer integration can affect the AEC industry and curricula (Heitmann et al. 2003; Smith 2003; Ketz and Hug 1998; Howard et al. 1989).

112 For example, Ketz and Hug (1998) investigated the existing approaches for integration of computer science as a foundation in the engineering curricula. They found that "there is a knowledge transfer gap between computer science

114 and engineering disciplines” and suggested that there should be consistent and adequate level of computer science in 115 engineering education. Howard et al. (1989) suggested that computer technologies can be used as intelligent tools to enhance automation, communication, bookkeeping, problem solving, and decision making in the AEC process.

117 Integration of these technologies into the AEC process will create a new knowledge, which needs to be transmitted 118 into educational programs to prepare engineers and architects for their future roles. Some studies have investigated the need for the issues and shortcomings in the organization and direction of computer usage and the teaching of computing technologies to civil engineering students (Henry 1992; Baker and Rix 1991; Grigg et al. 2004). For

121 example, Grigg et al. (2004) investigated the challenges of integrating computing into the civil engineering curriculum

122 and in conclusion suggested that given that the level of technology and practice of engineering increase in complexity 123 continuously this constant increase is making it difficult for educators to cover the required topics in depth. Therefore, 124 it is hard to find "the right mix of topics and courses for a changing curriculum.” Some other studies have examined 125 the share and content of subjects related to computing and information technology in AEC curricula (Smith 2012; 126 Baker and Rix 1992). For example Smith (2012) described a course on the fundamentals of computing taught to 127 second-year civil-engineering undergraduates in Switzerland for ten years. The outcomes suggested that through 128 adopting a strategy of teaching fundamental computer science concepts, relevant in engineering contexts, it is possible 129 to revise the engineering curricula to reflect aspects such as "increasing needs for wide-band competence and agility 130 requirements required for when new technology emerges.” Danijel and Tibaut (2005) introduced programs, such as 
the Erasmus master program, which is an IT focused postgraduate course with the objective of organizing the knowledge in the field of IT (including basic computer science and informatics courses in AEC) for developing an effective learning environment using distant learning technologies. Yu (2013) introduced a new course called "Architectural design" inclusive of digital technology and architecture where structure and teaching content of this course benefit from the basic computer science knowledge and technology. This course covers the computer aided design systems and increases the content of computer graphic principles of new buildings through theory and application. This course was designed to improve the students' skills to employ computing for architecture and design in their projects.

Other AEC researchers also focused on the evolution of the AEC industry and AEC education regarding the new computing trends, which have resulted in technological and institutional transformations and changes. These trends led to the emergence of approaches for integrating new technological innovations, topics, and issues in AEC education; such as design optimization and decision-support tools, educational tools, information modeling and management, simulation, visualization tools (Flager et al. 2009; Abrishami et al. 2013; Hopfe et al. 2006; Issa et al. 2005; Shi 1999), and innovative information technology (IT) and information systems (IS) for construction improvements

145 (Stewart and Daet 2002; Issa and Anumba 2007; Johnson and Gunderson 2009). Building Information Modeling 146 (BIM) is another emerging and now arguably mainstream technology used in the AEC industry. Some studies 147 investigated the level of integration of BIM into the AEC curricula and the level of exposure to BIM technology that 148 AEC curricula should provide to the students (Becerik-Gerber et al. 2011a; Cooksey 2011). The results of studies 149 conducted by Cooksey (2011) showed an increasing need for AEC programs to add BIM into the curricula. In addition, the results suggested that a BIM course should introduce the students to the general principles of BIM as well as the specific capabilities of BIM software packages. In addition, the authors conclude a BIM course should include 152 collaboration techniques in order to share information between disciplines. Other emerging technologies such as 153 intelligent transportation systems (ITS), most common application of IT to infrastructure; intelligent construction systems; applications of IT to the construction process; environmental monitoring and control systems, IT features 155 used in environmental systems, have been adopted in the AEC industry (Grigg et al. 2005). Grigg et al. (2005) 156 investigated how to integrate information technology into the civil engineering curriculum to prepare civil engineers 157 to implement these emerging technologies to plan, build, and operate civil engineering systems and provided some 158 recommendations. The results suggested that engineers need preparation in systems thinking and systems tools such 
as systems engineering, communication, modeling, network analysis, and problem-solving strategies in order to address the concerns regarding the fast moving changes in technology as they relate to civil infrastructure.

161 Investigating the level of knowledge engineers need to acquire regarding IT-based components, the authors' results

162 illustrated that students need to study a new range of technologies such as integrated control system, including 163 communication, control actuators, data, and decision components. Furthermore, the authors investigated what

164 engineers need to know for their work, the results revealed the need for study of a new further range of IT topics such 165 as "software and personal tools, and IT-based systems used in communications, organization management and design, operation, and maintenance” (Grigg et al. 2005). These new trends revealed and highlighted concerns related to the

167 preparation of students to operate effectively in the emerging and evolving AEC computing environments and how 168 future architects and engineers can best assimilate the advanced, yet fundamental knowledge of computing technologies appropriate for their professional AEC careers.

170 In order to address these concerns and to continue to address the needs and issues for advancing the AEC education 171 through curricular changes, the authors initiated a follow up survey in 2014. Further motivating the research is to 172 continue the work on a bi or tri-annual basis in order for the results to become a "longitudinal" study for the AEC and 173 its' educators; one that through its frequency will be able to encourage educators to keep pace. This paper reports on 174 findings of this 2014 survey and furthermore identifies trends based on the previous 2012 survey and the 175 aforementioned precursor surveys. Specifically, the authors investigated the evolution of computing in the AEC 176 curricula and the integration and level of computer science knowledge versus computer skills in the AEC curricula. In 177 addition, the authors investigated the similarities and differences between architecture, and engineering programs by 178 analyzing the data within and then across these disciplines. Goals include providing support in answering the following 179 questions: 1) what is the appropriate body of knowledge in computing skills and computer science an AEC 180 professional should master?; 2) where do we need to adjust the AEC curricula from skills-based learning to science181 based learning with respect to computing?; and 3) where does the current trend of AEC integration have a compounding effect on these curricular decisions?

\section{Survey Methodology}

184 To assess the evolution of computing in the AEC curricula a survey methodology was implemented for data collection. 185 The survey questions were generated by the authors, who teach courses and research actively in the AEC fields. The 
authors underwent several iterations regarding the type, amount and arrangement of the questions. The authors endeavored to carry forward the critical questions assessed from the 2012 survey and to enhance the survey structure to increase the quality of the data garnered. The authors structured the survey into multiple sections designed to investigate the topics of computing and their evolution within the AEC curricula. The survey included five sections: 1) program information; 2) evaluation of computing courses; 3) evolution of computing in AEC curricula; 4) computing skills vs. computer science knowledge; and 5) program evaluation and future plans. A cover letter and an

192 invitation to participate in the survey were sent via email. A link to the online survey administered through a webbased service (Qualtrics) was included in the cover letter. The invitation and subsequent reminder emails were sent to

194 the participants approximately three times during a four-month period. Our list of recipients was garnered from the 195 North American and European accreditation boards and within our own computing disciplines and scholarly communities.

\section{Survey Specifics}

198 The survey was designed to acquire responses most importantly for two computing issues in the current AEC curricula:

199 (1) evolution of computing in AEC curricula; and (2) evaluation of computer science versus computer skills in AEC 200 curricula. The survey was open for about six months from June to November of 2014.The researchers specifically 201 solicited curricular decision makers such as deans, department chairs and program directors (37\% of the respondents), 202 and faculty members (63\% of the respondents) from architecture, architectural engineering, civil engineering, civil 203 engineering technology, architectural engineering technology, construction engineering, construction engineering 204 technology, and construction management programs throughout North America, Europe, and Asia. A total of 187 205 responses were received. After cleaning the data, a total of 170 responses remained.

206 Half of the respondents were from North America (mostly from the U.S.) and half were from the other continents: 207 Europe (23\% of the respondents), Asia (19\% of the respondents), South America (5\% of the respondents), and 208 Australia (3\% of the respondents). The list of programs in the U.S. was obtained directly from the Accreditation Board 209 for Engineering and Technology (ABET), the National Architecture Accrediting Board (NAAB), American Council 210 for Construction Education (ACCE), and American Schools of Construction (ASC). The European contributions were 211 obtained through contacting members of the European Group for Intelligent Computing in Engineering (egice.com) 
212 and through the European architecture and computing communities. The number of recipients receiving the initial

213 email is approximately 680 . The response rate was approximately $28 \%$.

214 Demographic information regarding the programs included: program type (architecture, engineering, and 215 construction) and degrees offered (graduate vs. undergraduate). About the half of the programs were undergraduate 216 programs, totaling $48 \%$ of the respondents. Respondents that only had graduate programs accounted for $52 \%$ of the

217 responses. Fifty four percent of the respondents were from architecture programs and $46 \%$ of the respondents were 218 from civil engineering and construction programs (mentioned as engineering hereafter as the construction programs 219 were offered in the civil engineering departments).

\section{Survey Results}

221 In order to analyze the survey results, the authors examined the responses to each question, counted the number of 222 responses and computed the percentages for all questions. The overall rating for each computing skill or application 223 within a specific question was determined as a weighted average of the percentages. The weights ranged from 1 to 5 224 as specified in the survey questionnaires -- a higher rating indicates more important, more competent, more coverage, more sufficient, and or more expert. Using t-tests the authors conducted exploratory analyses to investigate 1) the

226 differences in the curricula across the three different AEC disciplines and 2) computing skills vs. computer science 227 knowledge components of the AEC curricula. The statistical results are expressed in terms of a p-value at $\alpha=0.05$. In 228 addition to reporting the results of the 2014 survey, the authors compared the results from 2014 survey with 2012 229 survey in order to evaluate the evolution and pace of change in AEC curricula, in the responding educators' opinions.

Evaluation of Computing Components of the AEC Curricula

\section{Computing Skills}

232 The evaluation of the number of computing skills related courses offered in the AEC curricula (Figure 1) indicated 233 that overall computing related courses make up 15\% of all programs. Compared to the 2012 survey, results show a $2342 \%$ increase in the computing content of the curricula in architecture and engineering programs. One hundred and 235 seventy respondents (91 from architecture and 79 from engineering) answered the question seeking the percentage of 236 computing skills related courses in the AEC curricula. Sixteen percent of the architecture and 14\% of the engineering 237 curricula were computing courses. The increase is more obvious in the undergraduate programs. The results of t-test 
analysis indicated that the difference between the percentages of computing skills related courses in the two AEC program types was marginally significant $(\alpha=0.05, \mathrm{p}=0.06)$.

Figure 1 - Percentage of computing skills related courses in AEC programs

241 Survey results indicate the importance of individual computing skills within the program curriculum, the competence

242 of students in each skill, and the level to which each computing skill is covered in the academic curricula. In the 2014

243 survey like in the 2012 survey, the authors are foregrounding the purposeful distinction between computing skills (e.g.

244 programming, commercial tools, etc.) and computer science (e.g. algorithms, database design, search and optimization, machine learning, data structures, network science, etc.).

Table 1- Analysis of importance-competence-coverage of computing skills in the AEC curricula (The weights for importance (1: Not Important, 2: Somewhat Important, 3: Neutral, 4: Important, 5: Very Important). For competence (1: somewhat unskilled, 2: unskilled, 3: novice, 4: expert, 5: very expert). For coverage (1: not covered, 2: introduced, 3: covered, 4: moderately covered, 5: extensively covered))

Table 1 presents the participants' opinions of the importance, competence, and coverage of computing skills in the AEC curricula. Survey results indicate that the respondents rated most of the skills as important (3.5 to 4) in the AEC programs; except programming and equation solvers which are rated as neutral (2.5 to 3.5) in both architecture and engineering programs, and specialized engineering software and spreadsheets which are rated as neutral just in architecture programs. This could be due to the fact that AEC students are expected to gain these computing skills outside the curriculum. In general, most of the computing skills are rated to be more important in engineering programs than architecture programs, except for computer aided drafting, presentation packages and parametric design, which are considered to be more important in architecture programs. It is noteworthy that most of the computing skills are considered to be more important at the graduate level than undergraduate level except for building information modeling (BIM) which is considered to be more important in the undergraduate programs. This is a result that requires further investigation through future data sets which will provide more historical perception of BIM from 2012 onwards. for most of the computing skills. Students are considered to be experts in computer-aided drafting in architecture programs, as well as spreadsheets in engineering programs. Students in architecture programs are believed to be more 
competent in most of the computing skills in comparison to the students in engineering programs, except for competency with spreadsheets, specialized engineering software, equation solvers, and programming. In addition,

267 graduate students are believed to be more competent in most of the computing skills in comparison to undergraduate

268 students.

269 Seeking to measure the perception of academic coverage for computing skills, the results revealed that respondents

270 believed that AEC curriculum has covered most of the computing skills in engineering. Results also indicated that

271 there are some skills that are just introduced in architecture programs, such as specialized engineering software,

272 programming, and equation solvers (1.5 to 2.5). In general, Computing skills are considered to be more important in

273 the engineering programs, however, the percentages of computing related courses in engineering programs is less than

274 the percentages of computing related courses in the architecture programs and students are less competent in the engineering program suggesting that more computing related courses should be integrated to the engineering curriculum.

In the 2012 survey, the authors created a benchmark for assessing the trend of computing adoption in the AEC curricula. Comparisons of the results of the 2012 and 2014 surveys using two sample t-test show that there is no significant difference in the importance of the computing skills and coverage of curricula for these skills between the results of these two surveys. However the competence of the students in these skills has decreased considerably.

\section{Computer Science Knowledge}

282 Computer science knowledge includes fundamental topics in computational complexity and the study of representation and reasoning strategies. Such topics are expected to have an important impact on decisions related to computing during the careers of current AEC students (Smith 2012). In that regard the expectation is for AEC educators to understand, teach, develop, and apply more scientific computing methodologies in their regular curricular content. This will result in architects, engineers, and construction professionals who are agile when new technology emerges. It will also lead to the development of future computing tools that are easy to use and modify while being able to scale to particular, complex and large AEC applications. The results of this survey can contribute to developing a plan for AEC programs to design courses that equip students with comprehensive knowledge of application of representations and algorithms as a problem solving approach in the AEC. Investigating the respondents' perceptions of the importance of the computer science knowledge in their respective programs, 170 responses were received (91 
responses from architecture and 79 responses from engineering). The survey results indicated that overall $6.3 \%$ of all AEC programs offer courses that are related to computer science, which shows $1.3 \%$ increase compared with the results of the 2012 survey. Engineering programs at the graduate level lead the number of courses (7.9\%) followed by architecture graduate programs (7.7\%). At the undergraduate level, the architecture programs lead the number courses (5.7\%) followed by the engineering programs (3.7\%).

\section{Figure 2 - Percentage of the courses that are related to computer science knowledge}

In general, the 2014 survey results show an increasing trends in the percentages of computer science knowledge related courses in the different program types and levels when compared with the 2012 survey, especially in architecture programs. However, the results of the t-test indicated that the percentages of computer science related courses (in different program types in the AEC curricula) do not differ significantly $(\alpha=0.05, p=.213)$. In addition, the results of t-test revealed that the percentage of computing skills related courses compared to computer science related knowledge courses are significantly larger at $(\alpha=0.05, \mathrm{p}=0.000)$, as expected.

Table 2 shows the participants' opinions about the importance, competence, and coverage of computer science knowledge in the AEC curricula. Investigating the importance of the computer science knowledge shows that, in general, respondents considered the computer science knowledge as more important in engineering programs than in architecture programs. Computer science knowledge is considered as neutral in most of the computer science categories. The importance of computer science knowledge in the architecture programs varies from somewhat important to important, indicating less consensus. The results also indicated that respondents believe that application of the computer science knowledge is more important at the graduate level in comparison with the undergraduate 311 level.

Competence of the students in computer science is variable in different programs and no specific pattern can be observed. Students are judged to be unskilled in most of the computer science areas, except for computer graphics and 314 geometric modeling, and computational mechanics in which the students are novice in engineering programs. The 315 responses indicate that the students are more competent in graduate programs than undergraduate programs. The 316 coverage of computer science varies across different programs and most of the computer science knowledge concepts

317 are perceived as just introduced in the AEC programs, except for the computer graphics and geometric modeling in 318 architecture, and computer graphics and computational mechanics in engineering, which are perceived to be covered. 
This correlates with why students are found to be more competent in these topics. Results also indicate that computer science is covered more thoroughly in graduate programs.

321 In general, respondents rated computer science knowledge as less important than computing skills and students are 322 believed to be less competent in the computer science knowledge than the computing skills. As expected responses 323 also indicate there is less coverage for computer science knowledge compared to computing skills in the AEC 324 curricula. It is important to note that where there is more coverage of computer science knowledge topics, students 325 are more competent in these topics. These results show that respondents have not understood the importance of the scientific concepts of computing in educating students around AEC applications.

Table 2 - Analysis of importance-competence-coverage of computer science knowledge in the AEC curricula (The knowledge importance within the program curriculum (1: Not Important, 2: Somewhat Important, 3: Neutral, 4: Important, 5: Very Important). The competence of student knowledge (1: somewhat unskilled, 2: unskilled, 3: novice, 4: expert, 5: very expert)). The knowledge coverage within program curriculum (1: not covered, 2: introduced, 3 : covered, 4: moderately covered, 5: extensively covered))

With respect to understanding which programming languages predominate in the AEC curricula, the authors queried the participants to identify the programming languages that are taught in their programs. A total of 170 participants (91 from architecture and 79 from engineering programs) answered this question. Table 3 presents the ranking of the top ten programming languages in all of the AEC program types. The results show that in general, Matlab and Java are taught more compared to other languages in the AEC curricula. Similar to the 2012 survey, architecture programs still cover HTML more at the undergraduate level whereas Java and python are covered more at the graduate level.

339 Engineering programs cover Matlab, $\mathrm{C}++$ and Java more than the other languages at both graduate and undergraduate 340 levels. These trends are consistent with the trends that are observed in the computing curricula showing a growing 341 trend toward use of "safer" or "more managed languages" (for example, use of Java instead of C), as well as the use 342 of “more dynamic languages”, such as Python or JavaScript (Computer Science Curricula 2013; Computing curricula 343 2001). Monitoring the coverage and shifts in programming languages the authors believe is an important trend to 344 measure as it indicates emphasis on computer science as a fundamental skill but as well allows for discussion of links 345 to industry application development. 


\section{Computing Skills vs. Computer Science Knowledge}

The authors also inquired about the respondents' perceptions about the importance of the knowledge of "scientific" computing concepts for preparing architects, engineers and construction professionals for future developments of information technology for the AEC. A total of 164 responses were received (88 responses from architecture and 76 responses from engineering programs). The survey results indicate that most of the respondents considered computer science as important or very important in both architecture (68\%) and engineering and programs (76\%). The results of the t-test showed that the respondents' perceptions of the importance of the knowledge in scientific computing concepts for preparing architects and engineers for future developments in information technology do not differ significantly in architecture and engineering programs $(\alpha=0.05, \mathrm{p}=0.389)$. Conducting two sample t-test, the results show that there is no significant difference in the importance of the knowledge in scientific computing concepts in respondents' perceptions during the last two years $(\alpha=0.05, \mathrm{p}=0.749)$.

In another attempt to evaluate the relevance of computer science versus computer skills, the authors asked the respondents to rate the importance of the computing skills versus computer science knowledge in preparing students for a future within the AEC. One hundred and seventy responses (91 from architecture and 79 from engineering programs) were received. Overall, 89\% of all programs said computing skills are very important or important to the future of the AEC educational programs, which shows a 9\% increase compared to the results in the 2012 survey (significantly more than the results of the 2012 survey $(\alpha=0.05, p=0.049)$ ). Ninety three percent of the respondents in architecture and $85 \%$ of the respondents in engineering programs considered computing skills as very important or important to the future of the AEC curricula, which shows an increasing trend in the respondents' perceptions of the importance of the computing skills (Figure 3). It is noteworthy that the increase in architecture programs (15\%) is more considerable compared to the engineering programs (6\%): this is likely due to a paradigm shift occurring within architectural education, which is moving away from drawing and 2D practices towards 3D modeling as well as analysis and design automation (parametric and algorithmic design) within the core educational components. Computing skills are also perceived to be more important at the graduate level (80\% of the respondents considered it as important) than at the undergraduate level ( $51 \%$ of the respondents considered it as important). The results of the t-test indicated that that the perceptions of the respondents in the architecture programs regarding the importance of 
computing skills in preparing students for a future within the AEC significantly differ from the perceptions of the respondents in the engineering programs $(\alpha=0.05, p=0.042)$. Further analyzing the survey results using t-test showed that the respondents' perceptions of the importance of computer science knowledge in preparing students for a future within AEC in the two program types are not significantly different $(\alpha=0.05, p=0.883)$. The importance of computer science knowledge increases as the level of program increases. In comparison to the 2012 survey, a decreasing trend has been seen in the perceptions of the respondents regarding the importance of the computer science knowledge for preparing students for a future within the AEC (Figure 3) although the differences between the 2012 and 2014 surveys are not significantly important $(\alpha=0.05, p=0.247)$. In general, the respondents rated computer science knowledge as less important than the computing skills. The t-test revealed that there was significant difference between the importance of computing skills and computer science knowledge in the AEC curricula $(\alpha=0.05, \mathrm{p}=0.000)$.

\section{Figure 3 - Importance of computer skills vs. computer science knowledge for preparing students for a future}

\section{within the AEC}

\section{Evolution of Computing Skills Since 2002}

The results of this survey can be used to develop benchmarks to evaluate the evolution of computing in the AEC curricula going forward. The first surveys covered civil engineering programs solely. Starting with the 2012 survey, the authors covered more inclusively AEC educational programs in order to begin to track integration issues believed to be important to the future of AEC curricula. Here, to evaluate the evolution of computing in the AEC curricula, the authors compare the results of the 2014 survey with the 2012 (Gerber et al. 2013) and 2002 (Abudayyeh 2004) surveys to assess the computing components of specifically civil engineering education. Since the original surveys only considered computing in civil engineering curricula, the focus in this part is on the 2014 and 2012 responses that cover this field. To be consistent with the recent studies, educators' perspectives are used from the 2002 survey to discuss the importance, competence, and coverage of the computing skills for students. The numbers of respondents vary across these three surveys: 44 responses for 2002 survey, 57 responses for 2012, and 79 responses for 2014 survey were received. The weights range from 1 to 5 where a higher rating indicates more importance, competence, and coverage. A comparison of the importance ratings from the 2014 survey and 2002 survey indicates an overall slight increase in the importance of computing skills during the past 12 years although the difference is not significant except for the subject of collaborative environments. The increased emphasis on the importance of design methods and 
interdisciplinary approaches might be one of the reasons explaining the significant increase in the importance of collaborative environments. It is also noteworthy that the importance of spreadsheet and word processing has decreased slightly. Table 4 illustrates a comparison of the ratings of the importance, competence and coverage for each computing skill of the 2014 and 2012 surveys with their corresponding ratings from the educators' perspectives in the 2002 survey.

Table 4- Comparison of Importance, competence, and coverage of computing skills in the civil engineering curricula (2002-2012-2014) (The knowledge importance within the program curriculum (1: Not Important, 2: Somewhat Important, 3: Neutral, 4: Important, 5: Very Important). The competence of student knowledge (1: somewhat unskilled, 2: unskilled, 3: novice, 4: expert, 5: very expert)). The knowledge coverage within program curriculum (1: not covered, 2: introduced, 3: covered, 4: moderately covered, 5: extensively covered))

Building information modeling (BIM) was not measured in terms of importance, competence and coverage in the previous 2002 and 2012 surveys but it is ranked as the most important topic in the 2014 survey, and is an obviously prominent computing skill to continue to track as it is understood as necessary and now fundamental to the AEC. The comparisons indicate that the importance of most of the computing skills has increased when comparing 2002, 2012 and 2014 surveys except for spreadsheet and word processing (note that the differences in the importance of the computing skills, competence of the students in these skills and coverage of curricula for these skills are not significantly different in 2012 and 2014 surveys). The results also similarly show increase in percieved competence of the students in the computing skills and coverage of the curricula for these skills. Increase in the application of some existing software such as LaTeX might explain why the importance of some traditional skills such as spreadsheet and word processing has decreased and students have become less expert in these skills. In addition the decrease in

421 the level of coverage for these skills might be another reason explaining why students have become less expert in 422 these skills. The coverage results from the 2002, 2012, and 2014 surveys revealed that the rankings of some computing 423 skills in terms of coverage have changed considerably; for example programming ranking has changed from 3 to 8; 424 parametric design has changed from 6 to 10; and electronic communication ranking has changed from 10 to 7 . In 425 general, comparison of the results of the 2002, 2012, and 2014 showed an increasing trend in importance, competence, and coverage during 2002 and 2012 but a decreasing trend has been seen since 2012. 


\section{Evaluation of Students' Computing Abilities}

428 For the evaluation of current and desired computing abilities of students, 170 responses (91 from architecture and 79 429 from engineering programs) were received. The survey results illustrate that $66 \%$ of architecture and $43 \%$ of 430 engineering programs considered students to be currently above average or expert while $9 \%$ of architecture and $10 \%$ 431 of engineering qualified students' abilities as poor or below average. The rest of the respondents rated the students' 432 abilities as neutral. Comparing to the 2012 survey, we can see that in general respondents believed that computing 433 abilities of the students have increased significantly during the past two years $(\alpha=0.05, p=0.021)$ (Figure 4). The results of the t-test showed, there are marginally significant differences between the current computing skills abilities 435 of the students in the different AEC program types $(\alpha=0.05, \mathrm{p}=0.087)$.

436 In terms of computer science knowledge of students, the results again show consistency. Fifty nine percent of the 437 respondents in all programs rated the students' current abilities to be poor or below average and only $15 \%$ of the 438 architecture and $14 \%$ of the engineering programs believed the students to be expert or above average. These results 439 contradict the results in the 2012 survey, in which 5\% of architecture and $23 \%$ of engineering and programs considered the students to be above average or expert. Similar to the computing skills, the result of t-test reveal that there is no 441 significant difference in the current computer science knowledge abilities of the students in the AEC programs $(\alpha=$ $442 \quad 0.05, \mathrm{p}=0.730)$.

443 In general, the respondents rated the current computing skill abilities of students higher than their current computer 444 science knowledge abilities (Figure 4). Students' abilities in computer science knowledge are greater (22\% of the 445 respondents rated them as expert or above average) in graduate programs than undergraduate programs (only 5\% of the respondents rated them as expert or above average). The results of t-test confirm this observation and show that

447 the respondents' perceptions of current computing skills abilities of students differ significantly with their perceptions 448 of current computer science knowledge and abilities of students $(\alpha=0.05, \mathrm{p}=0.000)$.

449 In general, respondents believe that students in the architecture programs are more expert in the computing skills than 450 the students in the engineering programs. They also believe that students' expertise in computer science knowledge 451 has decreased in the engineering programs and increased in the architecture programs during the last two years. 452 Considering that computing skills and computer science knowledge are perceived to be more important in engineering 
programs than architecture programs, the results suggest that there is a greater need in engineering programs for increasing the computing content of the curriculum than architecture programs.

\section{Figure 4- Current and desired level of expertise of students in computing skills and computer science}

456 The survey results indicate that respondents believed that the students in architecture programs should be more expert

457 in computing skills than the students in engineering programs (desired abilities). Seventy percent of the respondents

458 in architecture and 51\% of the respondents in engineering programs believed that the students should be expert or 459 above average. The results of t-test indicate that respondents' perceptions of the desired level of expertise of students in computing skills differ significantly between architecture and engineering programs (Figure 4$)(\alpha=0.05, p=0.026$ ).

461 With regard to computer science knowledge, $26 \%$ of the architecture and $22 \%$ of the engineering programs rated the students' abilities as needing to be expert or above average. The t-test results show no significant difference between different program types in terms of their perceptions about the level of expertise students need to have in computer

464 science knowledge. In general, respondents believed that students should be more expert in computing skills than computer science knowledge. Here again, graduate students are rated to be more expert in both computing skills and computer science knowledge than the undergraduate students. The results of t-test indicate that there is significant

467 difference in the respondents' perceptions of the level of expertise that students need to have in computing skills and 468 computer science knowledge $(\alpha=0.05, \mathrm{p}=0.000)$.

\section{Program Evaluation and Future Plans}

470 The authors sought the topics of importance for the future of AEC curricula and asked the respondents to prioritize

471 these topics for their program categories. A total of 164 respondents answered this question (88 respondents from 472 architecture programs and 76 respondents from engineering programs).

\section{Table 5 - Top 10 important topics for future AEC education}

474 The results (Table 5) indicate that both programs considered BIM, visualization, computer aided drafting (CAD), and 475 simulation as very important topics for the future of AEC education. The same results were seen in the 2012 survey 476 for the first two topics of BIM and visualization. In looking for causality of these trends the authros have started to 477 look into pure computer science curricula trends and changes. A few of relvance to the AEC include observations such as an increasing emphasis on the use of CAD and visualization tools (Computer Science Curricula 2013; Computing 
curricula 2001), which might have influenced the AEC curricula. The authors also asked the respondents to prioritize the topics that they believe should be increased in the computer science content of teaching in the AEC curricula. Machine learning and data analytics (Big Data) is rated to be the most important topic. The increase in emphasis of the machine learning in the computing curricula in the past decade (Computer Science Curricula 2013; Computing curricula 2001) is likely another influence upon the priority topics observed by our respondents from the AEC. These results shown in Table 6 indicate that respondents still do not recognize the implicit links that many topics in computer science currently have to AEC applications. For example, databases and computer graphics are in the lower half of the priorities. This indicates that more effort is needed to communicate such links to curricula decision makers.

\section{Table 6 - Ranked priorities by Program of Computer science knowledge topics}

In both the 2012 and 2014 surveys, the authors assessed the participants' perceptions of how BIM has been integrated into the AEC educational programs by asking about where BIM is taught versus where BIM is planned to be taught. The 2014 survey results indicate that, architecture programs teach BIM mostly for modeling (91\%) followed by energy analysis (63\%) whereas engineering programs also mostly teach BIM for modeling (71\%) followed by BIM based collaboration (54\%). The comparison of the results from 2014 with the 2012 survey shows that in general, the trend of BIM integration into the AEC curricula does not meet what was perceived as planned for in the 2012 survey and the applications of some of the examined computing skills have decreased significantly over the past two years including modeling $(\alpha=0.05, \mathrm{p}=0.000)$, energy analysis $(\alpha=0.05, \mathrm{p}=0.043)$ and customization $(\alpha=0.05, \mathrm{p}=$ 0.006).

\section{Figure 5 - The planned and current areas where BIM is/will be taught (2014 compared to 2012)}

Using 2012 as an initial benchmark, the authors tracked the evolution of computing in AEC curricula and provide a benchmark for further evaluation of the status of computing education in order to support decision making for the future AEC curricula. The authors asked the respondents to rate the sufficiency of computing education to meet the demands of the AEC industry. A total of 164 respondents answered this question (88 responses from architecture and 76 responses from engineering programs). The t-test results indicate that the sufficiency of the computing education to meet the demands of the AEC industry does not differ significantly for the different program types $(\alpha=0.05, \mathrm{p}$ $=0.655$ ). Thirty-five percent of the architecture and 33\% of the engineering programs considered computing education as sufficient or somewhat sufficient whereas, $48 \%$ of the architecture and $47 \%$ of the engineering programs believed 
that computing education is not sufficient or somewhat insufficient to meet the demands of AEC industry (Figure 6). Participants believed that computing education is more sufficient in graduate level programs (37\%) than undergraduate level programs (34\%).

\section{Figure 6- How sufficient is computing education to meet the demands of AEC industry}

In order to characterize the context of decisions related to future plans for the AEC curricula, the respondents were asked to list the barriers to incorporate computing into the AEC curricula and provide solutions to address the gaps in the computing education. No room in the curricula, inadequate resources to make the curriculum change, lack of adequate funding, and inadequate criterion were recognized as the main barriers. In addition, increasing the computing skills and computer science knowledge of the curricula, and redesigning traditional AEC courses based on new skills and demands were suggested as solutions to address the gaps in the computing education. The respondents were also asked about their opinions about what can be done to better prepare the students for their future jobs. The main recommendations included: 1) improving computing skills and computer science knowledge of students to meet the demands of the industry; 2) improving communication between the academicians and professionals; 3) adjusting computing content of the AEC curriculum with the needs of the industry; 4) adding courses to curriculum based on industry expert recommendations; and 5) asking professionals to teach computing related courses in academia. These barriers, solutions and recommendations confirm the earlier assertion that the lack of awareness of the importance of computer-science principles prevents AEC educational decision makers from assigning a high enough priority to increase computing teaching emphasis.

\section{Discussion and Conclusions}

This paper assesses the evolution of computing in the AEC curricula through seeking educators' views related to the computing components of the AEC curricula, through establishing trends important to measure, and through comparing these trends with the results from the 2012 survey and earlier data sets. In addition, this research provides insight and reveals issues and barriers that are most relevant to and for prioritizing for the AEC curricula decisionmaking. The research furthermore highlights a gap in the understanding, consensus and integration of computer science knowledge versus purely computer skills within the AEC curricula.

Assessment of computing components in the AEC curricula shows increasing trends in the percentages of both computing skills and computer science knowledge related courses in all program types and levels over the past two 
years. Although the results of the 2012 survey revealed the need for increasing the computing content of the AEC curricula, the results of the 2014 survey indicate the perceived importance of most of the computing skills and coverage

535 of the curricula for these skills have not changed significantly, while competence of the students in these skills, have 536 decreased since 2012.

537 Another important assessment is that educators are still neutral about the importance of computer science knowledge 538 within their curricula. The results suggest AEC educators believe that students are unskilled in most of the computer 539 science knowledge categories and indicate most of these categories are merely introduced in the AEC curricula. 540 According to Grigg et al. in 2004 the curriculum coverage for important foundational topics such as CAD, graphics, 541 and computational skills was not enough (Grigg et al. 2004). The evidence is consistent in the lineage of survey and 542 precedents that there is a greater need for computing within the AEC as expected but also with a consistent emphasis 543 for computing skills. Furthermore there is consistent lament amongst some AEC educators that there is too much 544 required content for an undergraduate or graduate degree and therefore, it is not to possible to include all topics in a 4-6 year curriculum, whether computer skills or computer science or a balanced combination of both. Furthermore, 546 computing tools are proliferating making it difficult for AEC educators to teach all of them. The data from both 2012 547 and 2014 highlight this as a key barrier to evolve the AEC curricula in general.

548 As it has been and remains a primary objective of our research to continue to measure and highlight the distinction 549 and comparison of computing skills with that of knowledge of relevant aspects of computer science as perceived by 550 AEC educators the data is here too, consistent and suggestive of a neutrality. Assessment of computing skills versus computer science knowledge shows that computing skills are judged to be more important than computer science

552 knowledge in the AEC curricula. While this is expected and reasonable considering the industry is a heavy user of 553 computer applications, it is also clear this will continue to lead to a lagging in innovation when it comes to the 554 development of purpose built methods and technologies specific to the AEC needs and challenges. The survey results 555 clearly support this conclusion and show an increasing trend in the respondents' perceptions of the importance of 556 computing skills for preparing students for a future within the AEC. The results indicate that most of the educators 557 concentrate on the professional criteria that must be met within the programs which we suggest is a reoccurring 558 challenge for the educators who making curricula decisions to evolve their course content adequately to meet the needs 559 of AEC beyond the near term horizon. 
Evaluation of current computing abilities of students indicates that students have become less competent in both computing skills and computer science knowledge over the past two years. This result is perhaps most alarming at

562 first glance, although this may be due to the rapid increase in tools and computing capabilities that the industry has 563 access to whereas academic programs have yet to keep pace. Results seem to validate this and show that respondents 564 believe that the computing content in our AEC education is not sufficient to meet the demands of industry and the 565 level of expertise of students should increase in both computing skills and computer science knowledge.

566 This survey has also been structured to measure the opinions related to fundamental aspects of computing education 567 for the AEC, including the priority of topics, tools and programming languages that are needed for the foundational 568 training of AEC students. These results indicate that respondents still do not recognize the implicit links that many 569 topics in computer science currently have to the AEC applications. Furthermore, the inclusion of measuring the status of new software and skill sets such as those relevant to BIM are assessed in order to compare the current situation in

571 the AEC curricula with previous years and therefore anticipate more appropriately the needs for upcoming years 572 through follow up surveys.

573 As with the previous survey our last set of questions in the survey was structured to determine the barriers to evolving,

574 the shortcomings, the needs and requirements for the AEC curricula. As expected and consistent with previous work, 575 predominant barriers to further incorporate computing into the AEC curricula are identified as the lack of room in the curricula; inadequate resources to make the curriculum change; inadequate funding; and inadequate criterion for

577 making informed curricular decisions.

\section{$578 \quad$ Limitations and Future Work}

579 The authors have run the 2014 survey on a two-year reoccurring cycle to establish what the authors anticipate will

580 become a longitudinal study. This paper is the first set of results that the authors present as being benchmarked to that 581 of previous surveys, specifically the 2012 results which also intrinsically reflect the previous work from 2002 and 582 1998, etc. Although the two-year period might not be the best frequency to evaluate the evolution in the AEC curricula,

583 it is an important benchmark for future work and reflects the speed of change occurring in industry and computer 584 science generally. Important to the work is a criticism that all the previous surveys (except the 2012 survey) focused 585 solely on the civil engineering curriculum and in light of overlaps, new construction delivery models, moves towards 586 tighter integration and coupling of design through to operation models, data and objectives within the entire AEC 
value chain, our work begins to adjust the focus away from the "silo-ing” that has been historically dominant. Having the results of the 2014 survey in conjunction with the 2012 benchmark, the authors will continue to be able to more

589 critically assess the frequency, structure, and adjustment to the questionnaire more intelligently for future 590 investigations. The results of the survey were reported based on 170 respondents. Although this represents a good 591 sample size and a steady increase in participation, there remain a few challenges including: 1) the disparity between 592 the number of the participants in the architecture and engineering programs ( $54 \%$ architecture and $46 \%$ engineering); 593 and 2) difficulty in obtaining identical respondents as educators move and change positions. In the future, the authors 594 will analyze targeting, response rates and consistency of responders more closely. These issues will be addressed by 595 increasing the sample size and by motivating more people to participate in the survey ideally through actively 596 illustrating the value of such data for curricula decision making. In the future, the authors plan to investigate more 597 extensively the causalities and to measure the factors leading the to the changes in perceived value of computing topics 598 and content for the AEC industry.

599 Acknowledgements

600 The authors thank the ASCE TCCIT and all the Architecture, Engineering, and Construction program educators 601 throughout the world whose participation made this study possible.

\section{References}

603 Abrishami, S., Goulding, J. S., Ganah, A., and Pour Rahimian, F. (2013) "Exploiting Modern Opportunities in AEC 604 Industry: A Paradigm of Future Opportunities." AEI 2013@ Building Solutions for Architectural Engineering, ASCE, $605 \quad 321-333$

606 Abudayyeh, O. Y, Hubo, C., Fenves, S. J., Law, K., O'Neill, R., and Rasdorf, W. (2004). "Assessment of the 607 Computing Component of Civil Engineering Education." Journal of Computing in Civil Engineering, 18 (3), 187-195.

608 Baker, N. C. and Glenn, J. R. (1991) "The Status of Computing in Civil Engineering: Curricula Vs. Practice." 609 Computing in Civil Engineering and Symposium on Data Bases, ASCE, 910-919.

610 Baker, N. C., and Glenn, J. R. (1992). "Computing in Civil Engineering: Current Trends and Future Directions." 611 Journal of Professional Issues in Engineering Education and Practice, 118 (2), 139-155. 
612 Becerik-Gerber, B., Gerber, D. J., and Kihong, K. (2011a). "The Pace of Technological Innovation in Architecture, 613 Engineering, and Construction Education: Integrating Recent Trends into the Curricula." Journal of Information 614 Technology in Construction, 16, 411-432.

615 Bouchlaghem, D., Huiping, S., Whyte, S., and Ganah, A. (2005). "Visualization in Architecture, Engineering and 616 Construction (AEC)." Automation in Construction, 14 (3), 287-295.

617 Burry, M. 2013. "Scripting Cultures: Architectural Design and Programming." John Wiley \& Sons.

618 Burry, M., Coulson, J., Preston, K., and Rutherford, K. (2001). "Computer-Aided Design Decision Support: 619 Interfacing Knowledge and Information." Automation in Construction, 10 (2), 203-215.

620 C++ [Computer software]. 〈http://isocpp.org〉 (September 24, 2014).

621 Ceccato, C, AADipl, MSc(CS), DIC, and MIEEE . (2005). "Integration: Master [Planner| Programmer| Builder]." 622 International Conference on Generative Art, < http://www. generativeart. com> (May. 20, 2015).

623 Ceccato, C. (1999). "Microgenesis. The Architect as Toolmaker: Computer-Based GenerativeDesign Tools and 624 Methods." Proceedings of the First International Generative Art Conference, Generative Design Lab at DiAP, 625 Politecnico di Milano University.

626 Computer Science Curricula. (2013). "Curriculum Guidelines for Undergraduate Degree Programs in Computer 627 Science." The Joint Task Force on Computing Curricula Association for Computing Machinery (ACM) IEEE 628 Computer Society.

629 Computing curricula. (2001). "Computer Science, Final Report, the Joint Task Force on Computing Curricula." IEEE 630 Computer Society and Association for Computing Machinery.

631 Cooksey, J. (2011). "The Integration of Building Information Modeling (BIM) into Civil Engineering Curricula." 632 Master of Science Thesis, Clemson University, December 2011.

633 Danijel, R., and Tibaut, A. (2005) "Computer science and IT in Civil Engineering curricula." 4 th International 634 Workshop on Construction Information Technology in Education, 35-41.

635 Flager, F., Welle, B., Bansal, P., Soremekun, G., \& Haymaker, J. (2009). Multidisciplinary process integration and 636 design optimization of a classroom building. Journal of Information Technology in Construction, 14, 595-612. 
637 Gerber, D. J., Khashe, S., and Smith, I. F. C. (2013). "Surveying the Evolution of Computing in Architecture, Engineering, and Construction Education." Journal of Computing in Civil Engineering, 29 (5).

639 Grigg, N. S., Marvin E. C, Darrell G. Fontane, L. S Thomas J. S, and Daniel K. S. (2004). "Integrated Civil Engineering 640 Curriculum: Five-Year Review." Professional Issues in Engineering Education and Practice. 130 (3), $160-165$.

641 Grigg, N. S., Marvin E. C., Darrell G. F., and Thomas J. (2005). "Information Technology in Civil Engineering

642 Curriculum." Professional Issues in Engineering Education and Practice. 131 (1), 26-31.

643 Heitmann, G., Avdelas, A., and Arne, O. (2003). "Innovative Curricula in Engineering Education." E4 Thematic 644 Network: Enhancing Engineering Education in Europe 100, Firenze University Press, Volume C.

645 Henry, R. (1992). "Civil Engineering Curriculum Computer Integration." Eighth National Conference on Computing 646 in Civil Engineering, ASCE, Dallas, 910-919.

647 Hopfe, C. J., Struck, C., Hensen, J., and Wilde, P. de. (2006) "Considerations regarding Decision Support Tools for 648 Conceptual Building Design." Proceedings of the 11th Int. Conf. on Computing in Civil and Building Engineering, 649 14-16.

650 Howard, H. C, Levitt, R. E, Paulson, B. C., Pohl, J. G., and Tatum, C. B. (1989). "Computer Integration: Reducing 651 Fragmentation in AEC Industry." Journal of Computing in Civil Engineering, 3 (1), 18-32.

652 HTML [Computer software]. 〈 http://html.com/〉 (September 24, 2014).

653 Irizarry, P., Meadati, P., and Gheisari, M. (2010). "The Need and Challenges for Interdisciplinary Education in AEC." 654 Construction Research Congress Banff, 226-235.

655 Issa, R. R. A., and Anumba, C. (2007). "Computing and Information Technology (IT) Research in Civil engineering656 Self-Fulfilling or Industry Transforming?" Journal of Computing in Civil Engineering, 21 (5), $301-302$.

657 Issa, R. R. A., Flood, I., and O’Brien, W. J. (2005). "4D CAD and Visualization in Construction: Developments and 658 Applications", Balkema, Rotterdam, The Netherlands, 281-284.

659 Java [Computer software]. 〈 http://www.oracle.com/technetwork/java/index.html 〉 (September 24, 2014).

660 Johnson, B. T., Gunderson, D. E. (2009) "Educating Students Concerning Recent Trends in AEC: A Survey of ASC 661 Member Programs." International Proceedings of the 46th Annual Conference. Associated Schools of Construction. 
662 Ketz, H and Hug, K. (1998). "Computer Science as a Core Subject in Engineering Education." Proceeding of 663 International Conference, Fachhochschule Reutlingen, 429-433.

664 MATLAB [Computer software]. 〈 http://www.mathworks.com/ > (September 24, 2014).

665 Python [Computer software]. 〈http://www.python.org〉 (September 24, 2014).

666 Qualtrics [Computer software]. Provo, UT, 〈http://www.qualtrics.com〉 (September 24, 2014).

667 Shi, J. J. (1999). "Computer Simulation in AEC and its Future Development." Proceeding of Berkeley-Stanford 668 Construction Engineering and Management Workshop, Stanford University, Palo Alto.

669 Smith, B. (2003). "The Intelligent Transportation Systems (ITS) Program: A Case Study in Successes and Failures of 670 Information Technology in Civil Engineering." Fourth Joint International Symposium on Information Technology in 671 Civil Engineering, 1-8. doi: 10.1061/40704(2003)2.

672 Smith, I. F. C. (2003). "Challenges, Opportunities and Risks of IT in Civil Engineering." Towards a Vision for 673 Information Technology in Civil Engineering American Society of Civil Engineers, Reston, VA, USA, 1-10.

674 Smith, I. F. C. (2012). "Integrating the Science of Computing into Undergraduate Engineering Curricula." Structures 675 Congress, Chicago, ASCE.

676 Stewart, R. A., Mohamed, S., and Daet, R. (2002). "Strategic Implementation of IT/IS Projects in Construction: A 677 Case Study." Automation in Construction. 11 (6), 681-694.

678 Svavarsson, D., Björnsson, H., Ekström, M., and Bergendahl, G. (2002). "Evaluating IT Investments in the AEC 679 Industry." Ninth European Conference on Information Technology Evaluation, 15-16.

680 Tibaut, A., Rebolj, D., and Čuš Babić, N. (2012a). "The Past and the Future of the European Master's programme in 681 Information Technology in Construction." 14th International Conference on Computing in Civil and Building 682 Engineering (14th ICCCBE), Moscow, Russia, 27-29.

683 Turk, Ž. (2006). "Construction Informatics: Definition and Ontology." Advanced Engineering Informatics, 20 (2), $684 \quad 187-199$.

685 Veeramani, D., and Russell, J. (2000). "Preparing the AEC Industry for the Knowledge Economy." Construction 686 Engineering and Management Workshop. 
687 Yu, F. D. (2013). "Curriculum Innovation Integration of Digital Technology and Architecture." Applied Mechanics 688 and Materials, 368-370, 7-10.

689 
690 Table 1- Analysis of importance-competence-coverage of computing skills in the AEC curricula (The

691 weights for importance (1: Not Important, 2: Somewhat Important, 3: Neutral, 4: Important, 5: Very

692 Important). For competence (1: somewhat unskilled, 2: unskilled, 3: novice, 4: expert, 5: very expert). For

693 coverage (1: not covered, 2: introduced, 3: covered, 4: moderately covered, 5: extensively covered))

\begin{tabular}{|c|c|c|c|c|c|c|}
\hline Computing Skills & Importance & Rank & Competence & Rank & Coverage & Rank \\
\hline $\begin{array}{l}\text { Building Information Modeling (digital representation } \\
\text { of physical and functional characteristics of a space) }\end{array}$ & 4.15 & 1 & 3.06 & 6 & 3.14 & 2 \\
\hline $\begin{array}{l}\text { Computer Aided Drafting (computer-aided creation, } \\
\text { modification, analysis, or optimization of a design) }\end{array}$ & 4.14 & 2 & 3.5 & 3 & 3.33 & 1 \\
\hline $\begin{array}{l}\text { Presentation Packages (packages used to display } \\
\text { information in the form of a slide show) }\end{array}$ & 4.07 & 3 & 3.78 & 2 & 2.99 & 4 \\
\hline $\begin{array}{l}\text { Word Processing (computer software application used } \\
\text { for composition, editing, and formatting of any sort of } \\
\text { written material) }\end{array}$ & 4.01 & 4 & 3.79 & 1 & 2.64 & 8 \\
\hline $\begin{array}{l}\text { Parametric Design (generative, computational, digital, } \\
\text { computer aided design) }\end{array}$ & 3.81 & 5 & 2.96 & 8 & 3.02 & 3 \\
\hline $\begin{array}{l}\text { Electronic Communications (computer mediated } \\
\text { communications) }\end{array}$ & 3.73 & 6 & 3.45 & 4 & 2.68 & 6 \\
\hline $\begin{array}{l}\text { Collaborative Environments (Computer-supported } \\
\text { cooperative work environment) }\end{array}$ & 3.72 & 7 & 3 & 7 & 2.62 & 9 \\
\hline $\begin{array}{l}\text { Spreadsheets (interactive computer application } \\
\text { program for organization and analysis of data in } \\
\text { tabular form) }\end{array}$ & 3.68 & 8 & 3.27 & 5 & 2.64 & 7 \\
\hline $\begin{array}{l}\text { Specialized Engineering Software (software that is } \\
\text { written for a specific task rather for a broad } \\
\text { application) }\end{array}$ & 3.38 & 9 & 2.79 & 9 & 2.75 & 5 \\
\hline $\begin{array}{l}\text { Programming (computer mediated formulation of a } \\
\text { computing problem to executable programs) }\end{array}$ & 3.18 & 10 & 2.52 & 11 & 2.59 & 10 \\
\hline $\begin{array}{l}\text { Equation Solvers (computer-aided programs used for } \\
\text { solution of systems of simultaneous non-linear } \\
\text { equations) }\end{array}$ & 3.04 & 11 & 2.54 & 10 & 2.4 & 11 \\
\hline
\end{tabular}

694

695 

curricula (The knowledge importance within the program curriculum (1: Not Important, 2: Somewhat Important, 3: Neutral, 4: Important, 5: Very Important). The competence of student knowledge (1: somewhat unskilled, 2: unskilled, 3: novice, 4: expert, 5: very expert). The knowledge coverage within program curriculum (1: not covered, 2: introduced, 3: covered, 4: moderately covered, 5: extensively covered))

702

\begin{tabular}{|c|c|c|c|c|c|c|}
\hline Computer Science Knowledge & Importance & Rank & Competence & Rank & Coverage & Rank \\
\hline $\begin{array}{l}\text { Computer Graphics (computer aided } \\
\text { representation of image data) }\end{array}$ & 2.84 & 4 & 2.99 & 1 & 2.91 & 1 \\
\hline $\begin{array}{l}\text { Geometric Modeling (computational } \\
\text { geometry and applied mathematics used for } \\
\text { mathematical description of shapes) }\end{array}$ & 2.9 & 3 & 2.56 & 2 & 2.47 & 2 \\
\hline $\begin{array}{l}\text { Computational Mechanics (computational } \\
\text { methods and devices to study events governed } \\
\text { by the principles of mechanics) }\end{array}$ & 3.6 & 1 & 2.26 & 3 & 2.22 & 3 \\
\hline $\begin{array}{l}\text { Algorithms and computational complexity } \\
\text { (mathematical characterization of the } \\
\text { difficulty of a problem which describes the } \\
\text { resources required by a computing machine } \\
\text { to solve the problem) }\end{array}$ & 2.81 & 5 & 2.15 & 4 & 2.12 & 4 \\
\hline $\begin{array}{l}\text { Data Base Concepts (computer-based } \\
\text { databases) }\end{array}$ & 2.72 & 7 & 2.14 & 5 & 2 & 5 \\
\hline $\begin{array}{l}\text { Object Representation and Reasoning } \\
\text { (computer based representations that capture } \\
\text { information used to solve complex problems) }\end{array}$ & 2.71 & 8 & 2.04 & 6 & 1.92 & 6 \\
\hline $\begin{array}{l}\text { Data Structures (computer data storage and } \\
\text { organization) }\end{array}$ & 3.14 & 2 & 2.04 & 7 & 1.9 & 7 \\
\hline $\begin{array}{l}\text { Optimization and Search (meta heuristic } \\
\text { method for solving computationally hard } \\
\text { optimization problems) }\end{array}$ & 2.74 & 6 & 1.99 & 8 & 1.86 & 8 \\
\hline $\begin{array}{l}\text { Knowledge Systems for Decision Support } \\
\text { (computer-based information system used to } \\
\text { support business or organizational decision- } \\
\text { making activities.) }\end{array}$ & 2.58 & 10 & 1.93 & 9 & 1.78 & 9 \\
\hline $\begin{array}{l}\text { Distributed Applications and Web (execution } \\
\text { of software on two or more computers in a } \\
\text { network) }\end{array}$ & 2.46 & 11 & 1.92 & 10 & 1.76 & 10 \\
\hline $\begin{array}{l}\text { Constraint Based Reasoning (automated } \\
\text { reasoning in artificial intelligence) }\end{array}$ & 2.59 & 9 & 1.73 & 11 & 1.63 & 11 \\
\hline $\begin{array}{l}\text { Machine learning and data analytics (Big } \\
\text { Data) (computational data training and } \\
\text { pattern recognition, analyzing and modeling } \\
\text { data) }\end{array}$ & 2.31 & 12 & 1.7 & 12 & 1.56 & 12 \\
\hline
\end{tabular}


Table 3- Top 10 languages that are taught in AEC programs

\# Architecture $\quad$ Engineering $\quad$ AEC

\begin{tabular}{|c|c|c|c|c|c|c|}
\hline & 2012 & 2014 & 2012 & 2014 & 2012 & 2014 \\
\hline 1 & Python & Python & Matlab & Matlab & $\mathrm{C}++$ & Matlab \\
\hline 2 & HTML & Java & $\mathrm{C}++$ & $\mathrm{C}++$ & $\begin{array}{l}\text { Java } \\
\end{array}$ & $\begin{array}{l}\text { Java } \\
\end{array}$ \\
\hline 3 & VB (.NET) & HTML & Java & Java & Matlab & $\mathrm{C}++$ \\
\hline 4 & $\mathrm{C}++$ & Others & $\mathrm{C}$ & VB (.NET) & Python & Python \\
\hline 5 & Java & $\mathrm{C}++$ & VB (.NET) & Fortran & VB (.NET) & HTML \\
\hline 6 & $\mathrm{C \#}$ & Matlab & Fortran & $\mathrm{C}$ & $\mathrm{C}$ & VB (.NET) \\
\hline 7 & $\mathrm{C}$ & VB (.NET) & Python & Python & HTML & Others \\
\hline 8 & Lips, Scheme & $\mathrm{C \#}$ & OpenGL & 'SPSS & Fortran & $\mathrm{C}$ \\
\hline 9 & Fortran & PHP & SAS & HTML & $\mathrm{C \#}$ & $\mathrm{C \#}$ \\
\hline 10 & Matlab & OpenGL & SPSS & $\mathrm{CH}$ & HTML & SPSS \\
\hline
\end{tabular}


Table 4- Comparison of Importance, competence, and coverage of computing skills in the civil engineering curricula (2002-2012-2014) (The knowledge importance within the program curriculum (1: Not Important, 2: Somewhat Important, 3: Neutral, 4: Important, 5: Very Important). The competence of student knowledge (1: somewhat unskilled, 2: unskilled, 3: novice, 4: expert, 5: very expert)). The knowledge coverage within program curriculum (1: not covered, 2: introduced, 3: covered, 4: moderately covered, 5: extensively covered))

\begin{tabular}{|c|c|c|c|c|c|c|c|c|c|}
\hline \multirow{2}{*}{ Skills } & \multicolumn{3}{|c|}{2002 Survey Ratings } & \multicolumn{2}{|c|}{2012 Survey Ratings } & \multicolumn{4}{|c|}{2014 Survey Ratings } \\
\hline & Importance & Competence & Coverage & Importance & Competence & Coverage & Importance & Competence & Coverage \\
\hline Spreadsheet use & 4.4 & 3.83 & 3.69 & 4.29 & 4.27 & 3.18 & 4.1 & 3.59 & 2.95 \\
\hline Word Processing & 4.19 & 4.1 & 2.91 & 4.18 & 4.27 & 2.81 & 4.1 & 3.77 & 2.71 \\
\hline $\begin{array}{l}\text { Computed } \\
\text { Aided Drafting }\end{array}$ & 3.91 & 3.15 & 3.32 & 3.94 & 3.77 & 3.55 & 3.99 & 3.38 & 3.38 \\
\hline $\begin{array}{l}\text { Electronic } \\
\text { Communications }\end{array}$ & 3.65 & 3.47 & 2.49 & 3.88 & 3.75 & 2.64 & 3.81 & 3.47 & 2.73 \\
\hline $\begin{array}{l}\text { Presentation } \\
\text { Packages } \\
\end{array}$ & 3.72 & 3.71 & 2.83 & 4.06 & 4.05 & 2.84 & 4 & 3.7 & 2.84 \\
\hline $\begin{array}{l}\text { Specialized } \\
\text { Engineering } \\
\text { Software }\end{array}$ & 3.5 & 2.5 & 2.7 & 3.91 & 3.88 & 3.44 & 3.77 & 3.04 & 3.06 \\
\hline Equation Solvers & 3.31 & 2.82 & 2.92 & 3.69 & 3.78 & 3.09 & 3.43 & 2.82 & 2.81 \\
\hline Programming & 3.02 & 2.15 & 2.56 & 3.77 & 3.53 & 3.35 & 3.37 & 2.57 & 2.72 \\
\hline $\begin{array}{l}\text { Collaborative } \\
\text { Environments }\end{array}$ & 2.95 & 2.14 & 1.91 & 3.88 & 3.48 & 2.79 & 3.85 & 2.89 & 2.56 \\
\hline $\begin{array}{l}\text { Parametric } \\
\text { Design }\end{array}$ & & & & 3.56 & 3.38 & 2.97 & 3.58 & 2.61 & 2.62 \\
\hline $\begin{array}{l}\text { Building } \\
\text { Information } \\
\text { Modeling }\end{array}$ & & & & & & & 4.28 & 2.81 & 3.13 \\
\hline
\end{tabular}


Table 5 - Top 10 important topics for future AEC education

\begin{tabular}{|c|c|c|c|c|c|}
\hline AEC & $\%$ & Architecture & $\%$ & Engineering & $\%$ \\
\hline $\begin{array}{c}\text { Building } \\
\text { Information } \\
\text { Modeling }\end{array}$ & $88 \%$ & $\begin{array}{c}\text { Building Information } \\
\text { Modeling }\end{array}$ & $85 \%$ & $\begin{array}{c}\text { Building } \\
\text { Information } \\
\text { Modeling }\end{array}$ & $92 \%$ \\
\hline Visualization & $73 \%$ & Parametric Design & $85 \%$ & Visualization & $68 \%$ \\
\hline $\begin{array}{c}\text { Computer Aided } \\
\text { Design }\end{array}$ & $69 \%$ & $\begin{array}{c}\text { Computer Aided } \\
\text { Design }\end{array}$ & $80 \%$ & $\begin{array}{c}\text { Simulation } \\
\text { (including } \\
\text { mechanics) }\end{array}$ & $57 \%$ \\
\hline Parametric Design & $67 \%$ & Visualization & $76 \%$ & $\begin{array}{c}\text { Computer Aided } \\
\text { Design }\end{array}$ & $57 \%$ \\
\hline $\begin{array}{l}\text { Simulation } \\
\text { (including } \\
\text { mechanics) }\end{array}$ & $66 \%$ & $\begin{array}{c}\text { Simulation (including } \\
\text { mechanics) }\end{array}$ & $75 \%$ & Optimization & $51 \%$ \\
\hline Analysis & $57 \%$ & Analysis & $67 \%$ & Analysis & $46 \%$ \\
\hline Optimization & $55 \%$ & Optimization & $59 \%$ & Parametric Design & $46 \%$ \\
\hline $\begin{array}{c}\text { Human-computer } \\
\text { interaction }\end{array}$ & $46 \%$ & Robotics & $53 \%$ & $\begin{array}{c}\text { Data } \\
\text { Interpretation }\end{array}$ & $43 \%$ \\
\hline Algorithms & $42 \%$ & $\begin{array}{c}\text { Automation: scripting } \\
\text { repetitive tasks }\end{array}$ & $52 \%$ & $\begin{array}{c}\text { Human-computer } \\
\text { interaction }\end{array}$ & $42 \%$ \\
\hline Sensor Networks & $41 \%$ & $\begin{array}{c}\text { Computer Aided } \\
\text { Drawing }\end{array}$ & $52 \%$ & $\begin{array}{c}\text { Risk Management } \\
\text { and Mitigation }\end{array}$ & $41 \%$ \\
\hline
\end{tabular}


754

\begin{tabular}{llll}
$\#$ & \multicolumn{1}{c}{ AEC } & \multicolumn{1}{c}{ Architecture } & Engineering \\
\hline 1 & $\begin{array}{l}\text { Machine learning and data analytics (Big } \\
\text { Data) }\end{array}$ & $\begin{array}{l}\text { Machine learning and data analytics } \\
\text { (Big Data) }\end{array}$ & Object Representation and Reasoning \\
\hline 2 & Distributed Applications and Web & Distributed Applications and Web & Distributed Applications and Web \\
\hline 3 & Optimization and Search & Optimization and Search & Optimization and Search \\
\hline 4 & Object Representation and Reasoning & $\begin{array}{l}\text { Knowledge Systems for Decision } \\
\text { Support }\end{array}$ & $\begin{array}{l}\text { Machine learning and data analytics } \\
\text { (Big Data) }\end{array}$ \\
\hline 5 & Knowledge Systems for Decision Support & Object Representation and Reasoning & Constraint Based Reasoning \\
\hline 6 & Data Structures & Data Structures & Knowledge Systems for Decision \\
\hline 7 & Constraint Based Reasoning & Data Base Concepts & Geometric Modeling \\
\hline 8 & Computational Mechanics & Computational Mechanics & Data Structures \\
\hline 9 & Data Base Concepts & Constraint Based Reasoning & Computational Mechanics \\
\hline 10 & Geometric Modeling & Geometric Modeling & Computer Graphics \\
\hline 11 & Computer Graphics & Algorithms and computational & Data Base Concepts \\
\hline 12 & Algorithms and computational complexity & Complexity & Algorithms and computational \\
& & & complexity \\
\hline
\end{tabular}




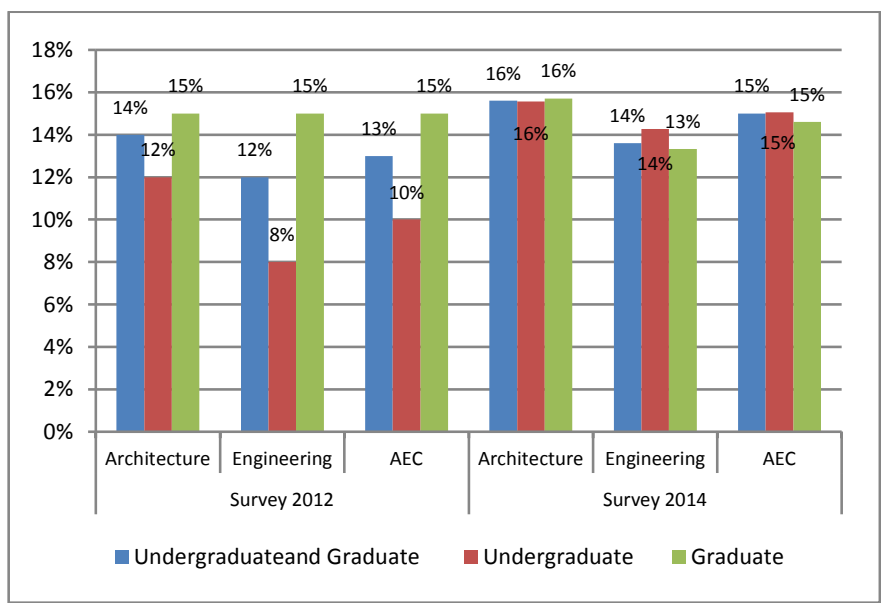

Figure 1 - Percentage of computing skills related courses in AEC programs 


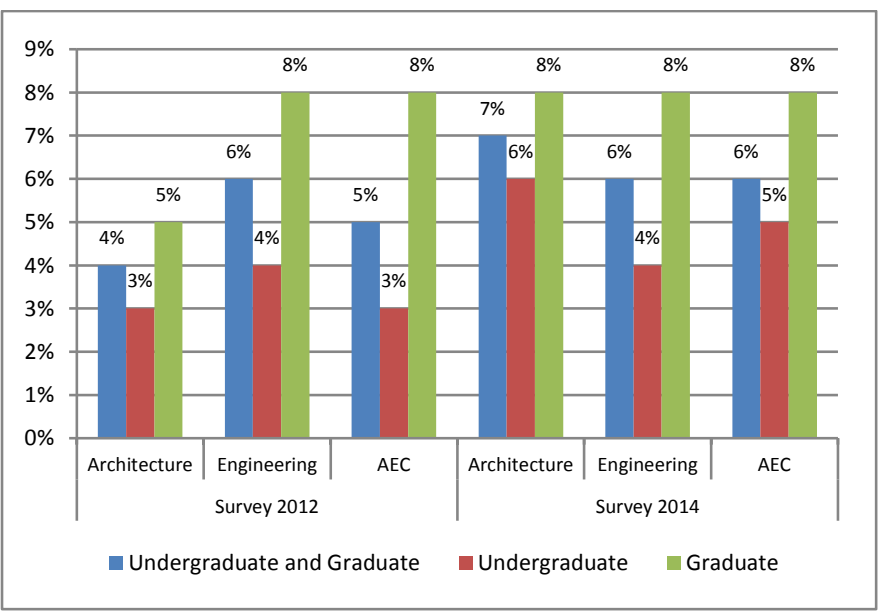




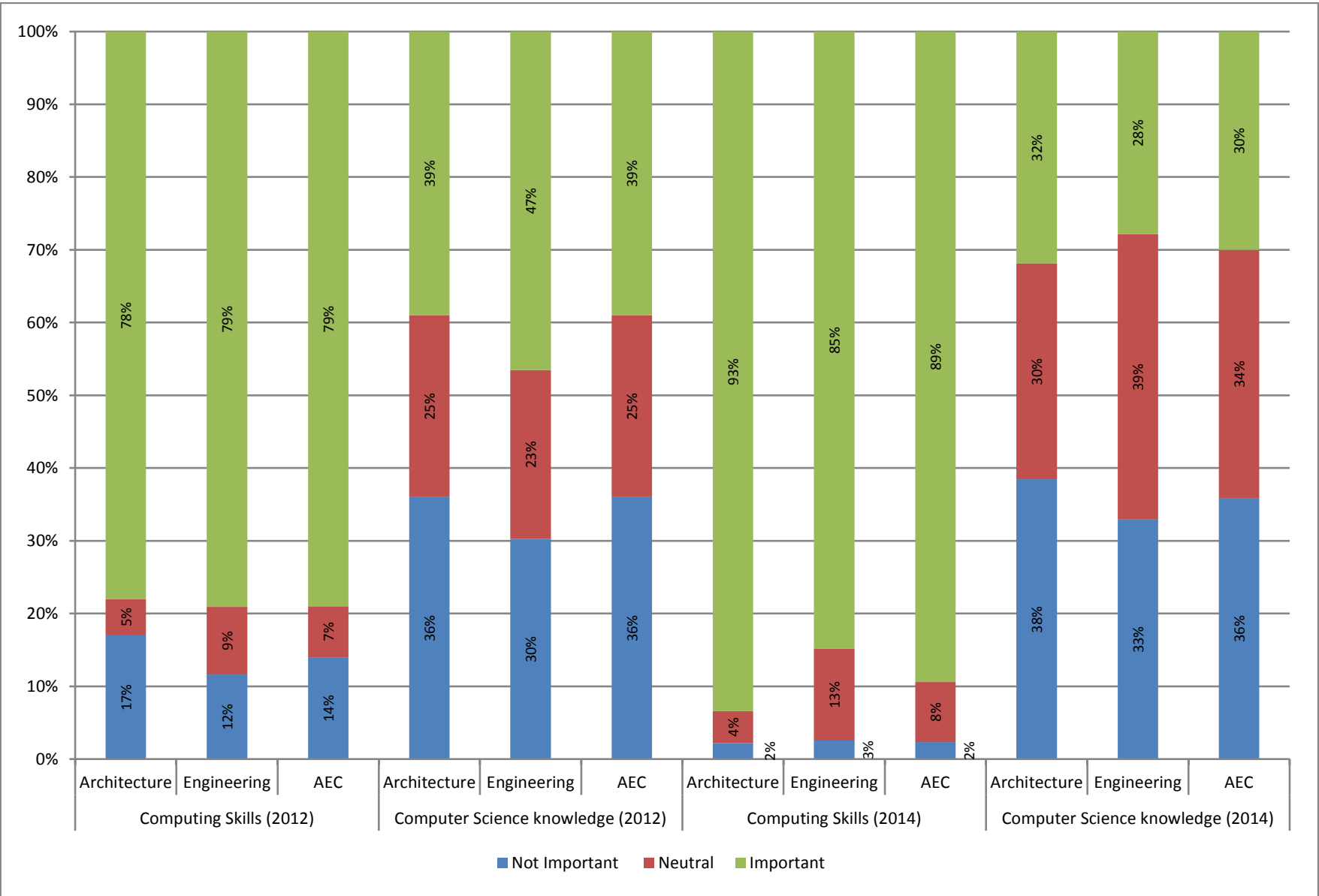

Figure 3 - Importance of computer skills vs. computer science knowledge for preparing students for a future 


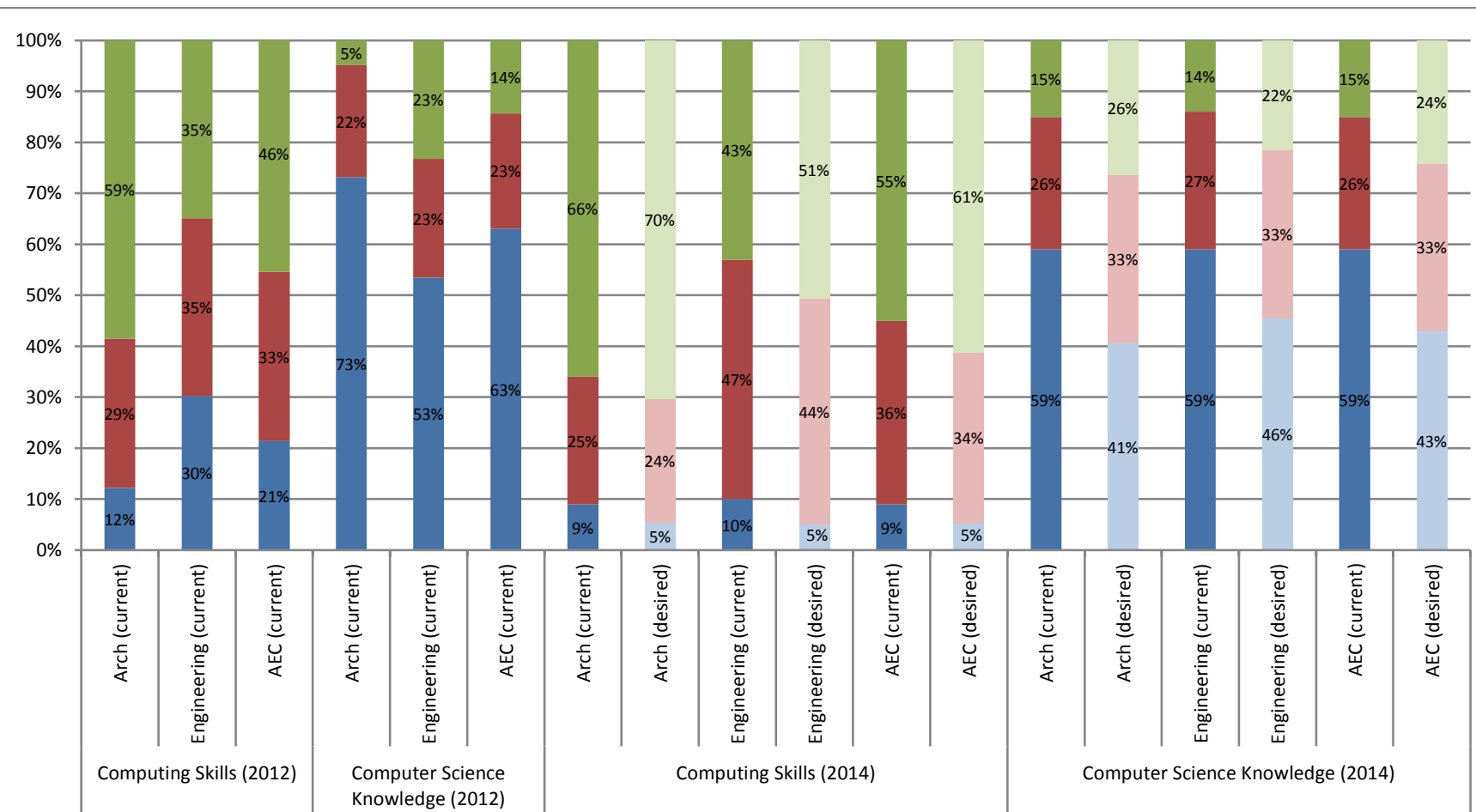

$\square$ Poor and Below Average (current) $\square$ Average (current) $\square$ Above average and Expert (current) $\square$ Poor and Below Average (desired) $\square$ Average (desired) $\square$ Above average and Expert (desired) 


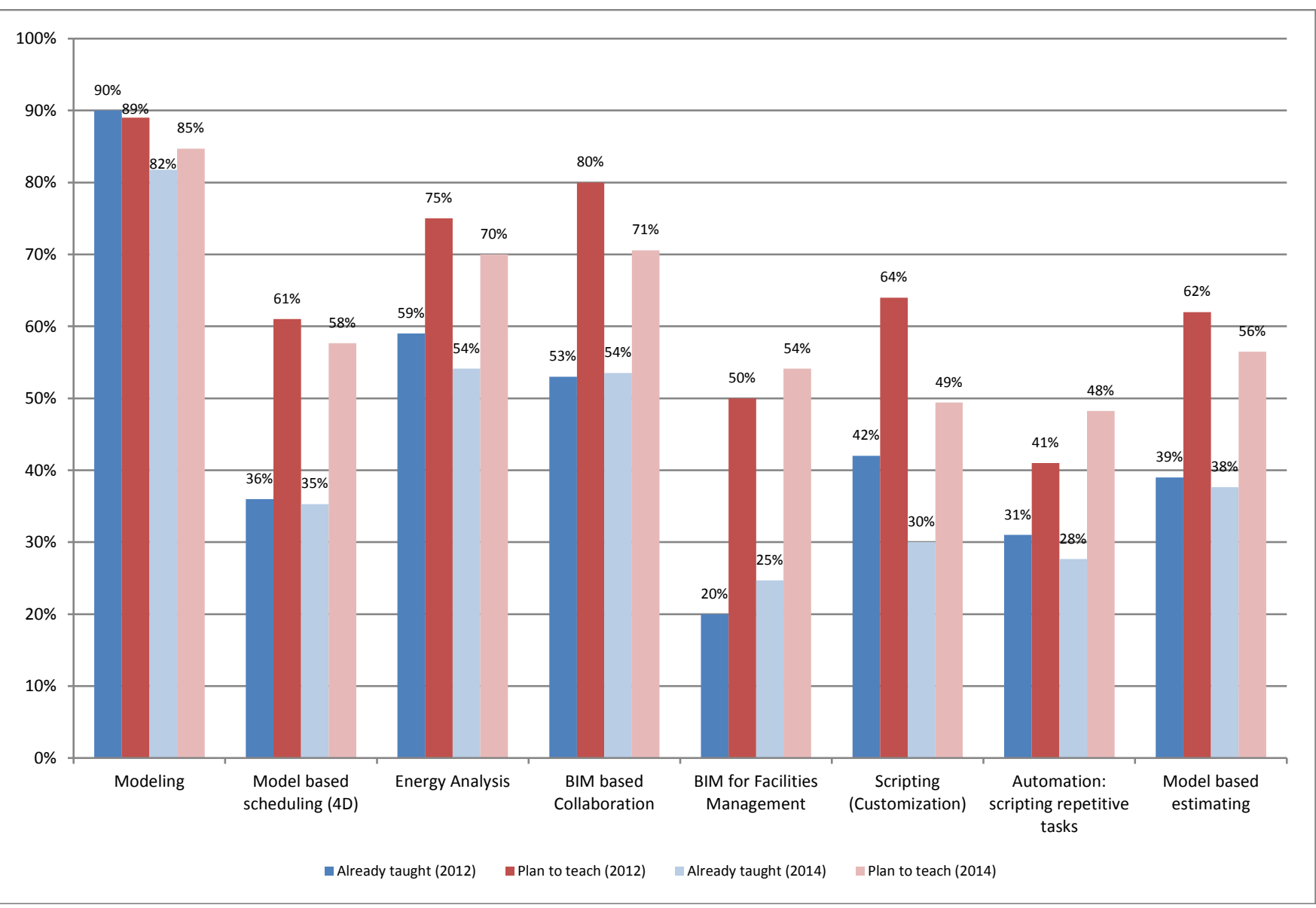

873

874

875

Figure 5- The planned and current areas where BIM is/will be taught (2014 compared to 2012) 


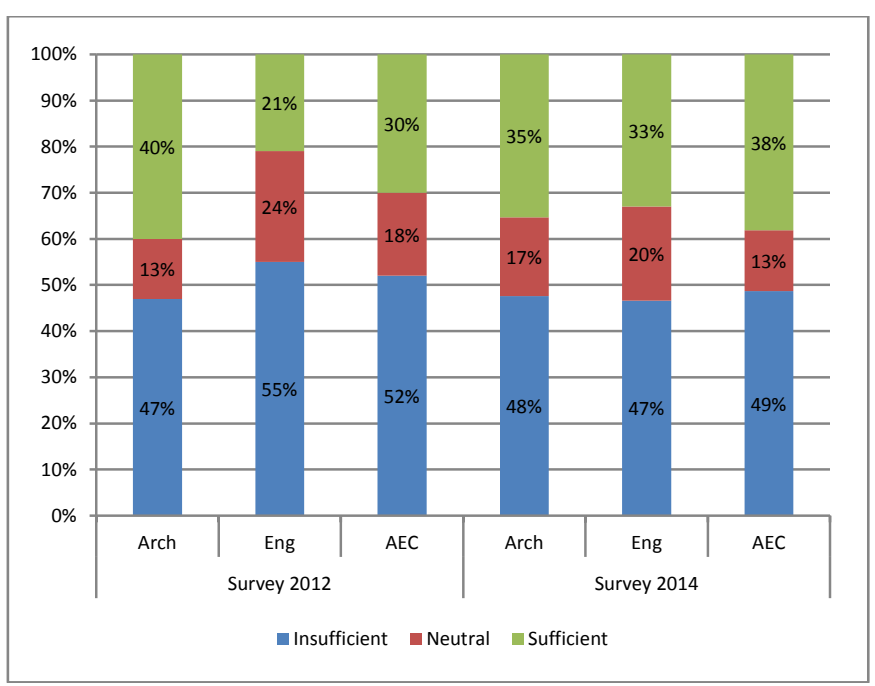

Figure 6- How sufficient are the computing education to meet the demands of AEC industry

897 